\title{
Characterization of wood-adhesive bonds in wet conditions by means of nanoindentation and tensile shear strength
}

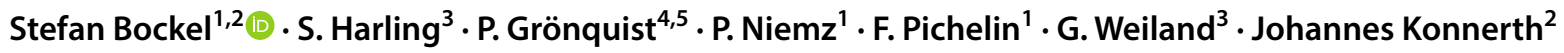

Received: 6 May 2019 / Published online: 13 April 2020

(c) The Author(s) 2020

\begin{abstract}
The performance of adhesive-hardwood bonds can often be sensitive to humidity and temperature variation. Therefore, it is frequently challenging to achieve standard requirements for structural applications. To gain a better understanding of the wood-adhesive bond, the properties of the individual constituents as well as the local interface of European beech (Fagus sylvatica $\mathrm{L}$.) wood cell walls in contact with structural adhesives were analyzed by means of nanoindentation. These results are compared to classical lap-shear strength. As adhesives two different one-component polyurethane adhesives (1C PUR) and a phenol resorcinol formaldehyde adhesive (PRF) were used. In one case, the beech wood was additionally pre-treated with an adhesion-promoting agent (primer) prior to bonding with 1C PUR. Beech wood joints were analyzed subsequent to several treatments, namely standard climate, after wet storage and in re-dried conditions. In addition, the influence of the primer on the hydroxyl accessibility of beech wood was investigated with dynamic vapor sorption (DVS). The lap-shear strength revealed good performance in dry and re-dried conditions for all adhesives on beech. Both polyurethane adhesives obtained deficits when tested in wet conditions. The use of a primer significantly improved the PUR performance in wet condition. DVS experiment demonstrated a decrease in hydroxyl group accessibility when using a high primer concentration. As novelty, nanoindentation was used for the first time to characterize the local wood-adhesive-interface properties in wet conditions. Nanoindentation showed that all tested 1C PUR perform quite similar in room climate, while PRF achieves considerable higher values for reduced E-modulus and hardness. Wet storage led to a considerable reduction in mechanical properties for all adhesives, while the highest relative change was observed for PRF. After re-drying, the adhesives re-gained a large part of their original mechanical properties in room climate. No distinct effect of the primer on the local micromechanical properties could be detected with nanoindentation in terms of specific work of indentation.
\end{abstract}

\section{Introduction}

The on-going trend towards mixed forests in Europe and a growing stock of hardwood challenges wood industry and science for an increasing material usage of hardwood. Until

Johannes Konnerth

johannes.konnerth@boku.ac.at

Stefan Bockel

stefan.bockel@gmail.com

1 Bern University of Applied Sciences, 2500 Biel, Switzerland

2 University of Natural Resources and Life Sciences, 3430 Tulln an der Donau, Austria

3 Collano AG, Sempach Station, 6203 Neuenkirch, Switzerland

4 Swiss Federal Laboratories for Materials Science and Technology, Dübendorf, Switzerland

5 Swiss Federal Institute of Technology, Zurich, Switzerland now, most of the hardwood is used for thermal energy production. Adhesive bonding can be one way to enable the use of hardwood for structural applications, thus using hardwood in a more profitable, competitive and sustainable way. However, some hardwood species still show difficulties in meeting requirements for structural standard testing methods, such as delamination resistance according to EN 302-2 (Konnerth et al. 2016). While higher strength of hardwood balances positive in wood-engineered products, the response to humidity reduces the competitiveness and potential of some hardwood species (e.g., beech wood).

One-component polyurethane adhesives (1C PUR) are being successfully used for structural applications using spruce as substrate. However, PUR is associated with comparably poor performance on some alternative wood species and some hardwoods, especially when tested for humid or very dry environments. In order to overcome these issues, adhesion deficits were addressed with the combination of 
different adhesion-promoting agents (primer) as reported in various studies (Ohnesorge et al. 2010; Amen-Chen and Gabriel 2015; Kläusler et al. 2014a, b). Richter (1999) described the general characteristics of primers by a polar part that enables strong intermolecular interactions, a hydrophobic spacer grid and a part that enhances the wetting with the adhesive. The application of primers can enhance the mechanical performance of 1C PUR bonds on hardwood in order to allow for complying with standard requirements (Kläusler et al. 2014a, b; Clerc et al. 2018). It was recently shown that a primer is capable of penetrating wood cells to a certain extent (Casdorff et al. 2018). However, the function of the primers at the local interface is not fully understood yet and demands further research. Similar to other references (e.g., Frihart 2012), in this context, the term "interphase" refers to the region within an adhesive bond where the adhesive penetrates the pores of the wood substrate. Within this interphase multiple local "interfaces" are present. The latter is defined as the direct (local) boundary between the wood cell wall and the adhesive.

Different approaches have been conducted to evaluate the performance of adhesives on wood (Amman et al. 2013; Konnerth et al. 2006; Kläusler et al. 2014a, b). Testing of single and pure adhesive films might not be able to display the real conditions in a bond line, since the surrounding wood affects the curing, mechanical relaxation and morphology as found by Ren and Frazier (2012). Therefore, investigations on wood-polymer-interactions are preferably conducted in a real joint.

Next to standardized tests, nanoindentation (NI) has shown to be a reliable technique that allows for investigating essential parameters relevant for adhesive bonding. The usage of nanoindentation to determine the properties of wood cell walls was introduced by Wimmer et al. (1997). Various studies on wood cell walls, adhesives and their interactions at the interphase followed and contributed to a better understanding of the joint performance (Amman et al. 2016; Zhang et al. 2015; Jakes et al. 2008; Konnerth et al. 2006; Rindler et al. 2018; Obersriebnig et al. 2013). NI has also been used in high humidity environment as shown by Jakes et al. (2015), but not yet applied to water-stored glue lines of hardwood in combination with a primer.

However, indentation values reported for studies on wood cell walls have to be interpreted carefully due to the threedimensional stress state in combination with the anisotropic nature of wood, as well as the importance of proper sample preparation (Konnerth et al. 2009). NI is capable of analyzing the properties of the individual components present in the interphase region of wooden bonds (e.g., Zhang et al. 2015; Konnerth et al. 2006) as well as the performance of the local interface at the micro-scale level (Obersriebnig et al. 2013). Studies in this field mainly addressed the interphase region of wood-adhesive-bonds in dry conditions or the influence of moisture on polymer films (Konnerth et al. 2010). Mechanical properties of adhesives are typically available in dry conditions as summarized by Stöckel et al. (2013). Literature using different climatic conditions is less frequently accessed (Rindler et al. 2018; Stöckel et al. 2013). Wood properties and their dependence on moisture have been well described at the macroscopic level (Niemz and Sonderegger 2017).

Little information is available on micromechanical properties including the influence of moisture and the performance of the interface at the local level, possibly due to a lack in available methodology. One possible approach to test interface performance was proposed by Obersriebnig et al. (2013). Knowledge of moisture-dependent mechanical properties of single constituents present in hardwood bonds could therefore help to better understand the behavior of the joint and possible influence of a primer. Next to the wood-adhesive-interactions, the influence of primer on the surface hydroxyl accessibility is of high interest. The available hydroxyl groups are assumed to play a crucial role in the physiochemical interactions in the wood bonding process (Frihart 2012). Dynamic vapor sorption analysis has shown to be useful for the determination of accessible hydroxyl groups of wood with deuterium (Sepall and Mason 1961; Thybring et al. 2017) and could be useful to describe the effect of primer application.

In the present study, the aim was a better understanding of the mechanisms contributing to moisture resistance of beech wood adhesive joints. Therefore, the following was investigated:

- Tensile shear strength and wood failure of beech wood bonds using different 1C PUR adhesives, partly in combination with a primer, and a PRF adhesive in dry, wet and re-dried conditions.

- Influence of adhesion-promoting agent (primer) and lack of extractives (hot water and hexane) on hydroxyl groups accessibility of beech wood by dynamic vapor sorption (DVS) analysis.

- Mechanical properties of individual regions (adhesive, wood cells) of beech wood bonds by nanoindentation in dry, wet and re-dried conditions.

- Performance of the local interface between cell wall and adhesive in dry, wet and re-dried conditions.

\section{Experimental}

\subsection{Wood}

European beech wood (Fagus sylvatica L.) with an average density of $700 \pm 34 \mathrm{~kg} / \mathrm{m}^{3}$ from one lot without any type 
of irregularities such as knots, heartwood or discoloration was selected and cut to lamellas of $10 \mathrm{~mm}$ thickness. The lamellas were stored in standard climate $\left(20{ }^{\circ} \mathrm{C} / 65 \%\right.$ relative humidity) until a moisture content of approximately $12 \%$ was reached. After conditioning, the material was planed with fresh knives down to $5 \mathrm{~mm}$, cut to size and bonded according to EN 302-1 for single lap-joints within $30 \mathrm{~min}$. Wood intended for nanoindentation and dynamic vapor sorption (DVS) experiments was used from one single board and from the same annual ring.

\subsection{Adhesives and wetting promoting agent}

Two commercial one-component polyurethane (1C PUR) adhesives were tested in this study and compared with a commercial phenol resorcinol formaldehyde (PRF) adhesive. The 1C PUR adhesives mainly differ by their reactivity (open time). 1C PUR B is recommended to use with a wetting promoting agent (primer) and the other system can be used without primer when bonding alternative wood species, for example beech or larch. The primer was used with 1C PUR B to create variant 1C PUR C. The use of primer is further described in the literature (Amen-Chen and Gabriel 2015; Richter 1999).

PRF has proofed to reliably bond wood for structural and outdoor applications (Dunky and Niemz 2002). The selection of adhesives and some of their processing parameters are listed in Table 1.

Table 1 Selected properties of adhesives and their processing parameters

\begin{tabular}{llll}
\hline Adhesive & 1C PUR (A) & 1C PUR (B) & PRF \\
\hline Viscosity @ 25 ${ }^{\circ} \mathrm{C}(\mathrm{mPas})$ & $20,000-30,000$ & 24,000 & $400-1500$ \\
$\begin{array}{l}\text { Open time (min) } \\
\text { Application }\left(\mathrm{g} / \mathrm{m}^{2}\right) \text { one }\end{array}$ & 160 & 70 & 120 \\
$\quad$ side & & 160 & 450 \\
$\begin{array}{l}\text { Closed assembly time } \\
\quad(\mathrm{min})\end{array}$ & 0 & 0 & 30 \\
$\begin{array}{l}\text { Pressure (MPa) } \\
\text { Press time (h) }\end{array}$ & 0.8 & 0.8 & 0.8 \\
\hline
\end{tabular}

\subsection{Longitudinal tensile shear strength and wood failure on beech wood}

The climatized and freshly planed lamellas were cleaned by compressed air prior to bonding. For the variants using a primer, the liquid primer was diluted in deionized water to a $10 \%$-solution for variant (C). To ensure homogenous primer distribution, the lamellas were transported with a conveyor belt and a constant feed speed through a selfmade spray application device. The defined amount of 20 $\mathrm{g} / \mathrm{m}^{2}$ was afterwards controlled by a scale without giving the solution time for evaporation. The used spread rate and concentration have recently been determined to be ideal for hardwood bonding (Clerc et al. 2018). After adhesive application the bonded lamellas were subsequently stacked into an apparatus to ensure precise pressure distribution and pressed in a hydraulic press (Lindenberg, Altendorf, Switzerland) for $10 \mathrm{~h}$ at $0.8 \mathrm{MPa}$ at ambient temperature for all adhesive systems. After pressing, the bonded lamellas were stored in standard climate for three weeks to ensure complete curing and sample conditioning. Subsequent to specimen treatment described in Table 2, lap joint specimens were tested in tensile shear mode according to EN 302-1 using a universal testing machine (Zwick $30 \mathrm{KN}$, Ulm, Germany). Specimens were tested in load-controlled mode at $2 \mathrm{kN} / \mathrm{min}$. For each variant and treatment, 15 specimens were tested and compared with solid beech wood references using the same specimen geometry, but without an adhesive bond line. Wood failure percentage (WFP) was determined visually in $10 \%$-steps.

\subsection{Dynamic vapor sorption analysis}

For the gravimetric determination of hydroxyl group accessibility, the dynamic vapor sorption equipment (DVS-ET1, Surface Measurement Systems, London, UK) was used. The samples were prepared from one beech wood panel within the same annual ring. Approximately $10 \mathrm{~g}$ of early wood was separated with a razor blade and further cut into very thin sections. Any chemical modification to the wood cell wall is usually more pronounced in early wood than late wood. Therefore, early wood was chosen for this experiment.

Samples were dipped into solutions with distilled water and primer in the following concentrations $0.1 \%, 1 \%$ and $10 \%$ (based on weight). To determine the influence of wood
Table 2 Treatment of tensile shear strength samples according to EN 302-1

\begin{tabular}{ll}
\hline Treatment & Definition \\
\hline A1 & Testing in standard climate $20{ }^{\circ} \mathrm{C} / 65 \%$ relative humidity \\
A2 & 4 days immersed in cold water $\left(20 \pm 5{ }^{\circ} \mathrm{C}\right)$, testing of specimen in wet condition \\
A5 & Boiling in hot water for $6 \mathrm{~h}$, then $2 \mathrm{~h}$ cold water storage $\left(20 \pm 5{ }^{\circ} \mathrm{C}\right)$, condition \\
& in standard climate until original mass is reached, testing in dry conditions \\
\hline
\end{tabular}


extractives on the hydroxyl group accessibility, further samples were extracted (Automatic Solvent Extraction 200, Dionex, Reinach, Switzerland) with hot-water (at $100{ }^{\circ} \mathrm{C}, 1$ h) and hexane (at $60^{\circ}, 1 \mathrm{~h}$ ). For each variant, three replicates were tested. Specimens were dried at $0 \% \mathrm{RH}$ and $60^{\circ} \mathrm{C}$ for 6 $\mathrm{h}$ while purging with dry nitrogen gas to remove the wood's bound water. A $1 \mathrm{~h}$ stabilization time at $25{ }^{\circ} \mathrm{C}$ (deuteration condition) followed. Afterwards, samples were conditioned with $\mathrm{D}_{2} \mathrm{O}$ (Liquid $\mathrm{D}_{2} \mathrm{O} 99.9$ atom\% D, Sigma Aldrich, Buchs, Switzerland) for $10 \mathrm{~h}$ at $95 \% \mathrm{RH}$. Specimen weight was determined before and after conditioning and hydroxyl group accessibility was calculated from the corresponding difference. The number of accessible $\mathrm{OH}$ groups was quantified according to Väisänen et al. (2018) as follows:

$A=\frac{m_{f-} m_{i}}{m_{i} \times\left(M_{D}-M_{H}\right)}\left(\mathrm{mol} \mathrm{g}^{-1}\right)$

$\mathrm{A}$ is the accessible $\mathrm{OH}$ group content in dry mass of the sample $\left(\mathrm{mol} \mathrm{g}^{-1}\right) \cdot \mathrm{m}_{\mathrm{i}}$ is the dry mass of the sample before exposing it to $\mathrm{D}_{2} \mathrm{O}$ vapor $(\mathrm{g})$. $\mathrm{m}_{\mathrm{f}}$ is the dry mass of the sample after the $\mathrm{D}_{2} \mathrm{O}$ exposure $(\mathrm{g}) . \mathrm{M}_{\mathrm{D}}$ is the molar mass of deuterium $\left(2.014 \mathrm{~g} \mathrm{~mol}^{-1}\right) . \mathrm{M}_{\mathrm{H}}$ is the molar mass of hydrogen $\left(1.008 \mathrm{~g} \mathrm{~mol}^{-1}\right)$.

\subsection{Nanoindentation}

Samples for the nanoindentation experiments were obtained from one beech wood lamella of $10 \mathrm{~mm}$ thickness. It was stored in standard climate $\left(20^{\circ} \mathrm{C}, 65 \% \mathrm{RH}\right)$ and small parts of around $25 \times 25 \mathrm{~mm}$ were cut out with a chisel. Each time, two counterparts were used to create an adhesively bonded assembly. Prior to bonding, a fresh surface at its radial anatomical plane was created with the help of a rotary microtome (Leica RM2155, Wetzlar, Germany) in order to keep cell wall damage at a minimum level. The primer was applied to variant 1C PUR C with a spray bottle and its application weight was controlled with a scale before bonding with 1C PUR. Afterwards, the adhesive was applied with a spatula. For PRF, a closed assembly time of $30 \mathrm{~min}$ was used. Small screw clamps were used to pressurize both counterparts for $12 \mathrm{~h}$ and stored without clamps in standard climate for three weeks to allow for sufficient post-curing and conditioning of the sample. Samples for nanoindentation were cut out with a razor blade with a size of $5 \mathrm{~mm}$ length, $2 \mathrm{~mm}$ thickness and $2 \mathrm{~mm}$ width. The samples were then bonded by a two-component epoxy resin (UHU Plus Sofortfest, Bolton, Switzerland) to a metal disc with $12 \mathrm{~mm}$ in diameter to fit into the ultra-microtome sample holder. Further microtoming with diamond blades (Ultratrim and Histo, Diatome, Nidau, Switzerland) using an ultramicrotome (Ultracut-R, Leica, Vienna, Austria) ensured flat surface. To control surface quality and for pre-selecting proper indentation points, incident light microscopy (Axioplan 2, Zeiss, Jena, Germany) was used. To allow for testing multiple specimens simultaneously, samples were bonded to flat metal plates. Three samples at a time were surrounded by a polymer ring to enable storing the samples in water during the later indentation experiments. The prepared samples were clamped magnetically onto the indenter stage. All nanoindentation experiments were performed with a Hysitron TriboIndenter (Hysitron Inc., Minneapolis, USA) equipped with an extremely sharp cone-shaped tip with a total opening angle of $60^{\circ}$. The scanning probe microscopy mode of the indenter was used to control the precise positioning (Fig. 1) of the indents. As recommended by Obersriebnig et al. (2013), indents were performed in a displacement-controlled mode with a maximum indentation depth of $850 \mathrm{~nm}$. Load was applied in a three-segment load ramp with a load increase for $3 \mathrm{~s}$, peak load holding for 20 and $3 \mathrm{~s}$ of unloading.

Measurements were taken to analyze the individual components present in an interphase of a bond, namely the bulk adhesive, the wood cell wall (S2) and at the direct interface between the adhesive and the wood cell wall lumen (S3), as well as between the adhesive and the wood cell wall (S2) (Fig. 1).

For each climate condition and adhesive variant, eight wood cells were tested with eight indents. For bulk material properties, the obtained results were reduced E-modulus $\left(\mathrm{E}_{\mathrm{r}}\right)$ and hardness $(\mathrm{H})$, evaluated according to the method by Oliver and Phaar (1992). The specific work of indentation $\left(\mathrm{W}_{\mathrm{d}}\right)$ spent during each indent at the interface between adhesive and wood cell wall was determined by integrating

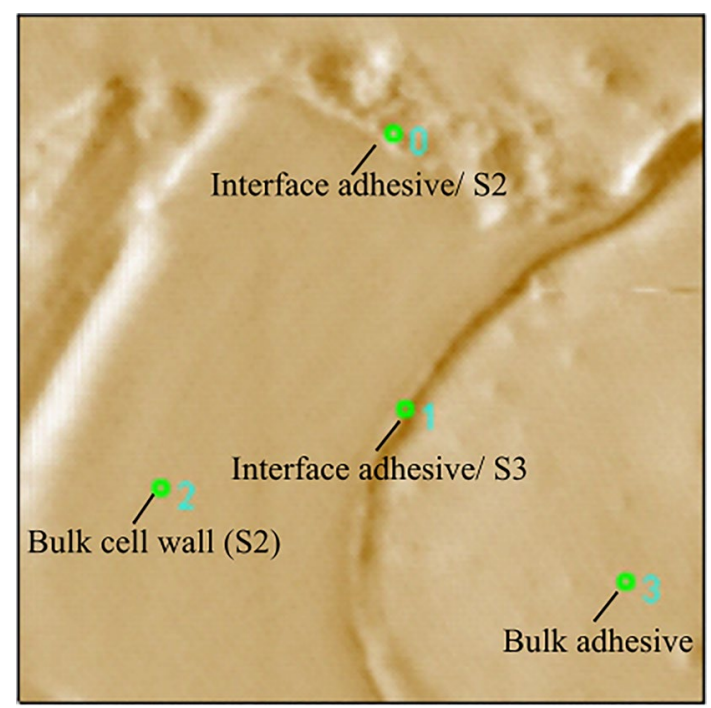

Fig. 1 Scanning probe microscopy image $\left(10 \times 10 \mu \mathrm{m}^{2}\right)$ of a beech wood cell wall surrounded by adhesive and intended indentation positions at interface adhesive/wood cell wall S2, interface adhesive/wood cell wall S3, bulk wood cell wall and bulk adhesive 
the total area under the load-displacement curve as proposed by Obersriebnig et al. (2012).

Statistical analysis of the results of nanoindentation and lap-joints on beech wood was conducted with a single factor variance analysis (ANOVA, 5\% confidence interval) with a post hoc least significant difference to allow comparison between the mean values of each adhesive variant.

\section{Results and discussion}

\subsection{Tensile shear strength and wood failure on beech wood}

The results of tensile shear strength and wood failure percentage (WFP) are shown in Fig. 2. After conditioning in standard climate, all adhesive systems were able to meet the standard requirement of $10 \mathrm{MPa}$ according to EN 302-1. PRF even surpasses solid wood in tensile shear strength and had the highest wood failure percentage $(90 \%)$ of all tested adhesives. While the PRF joints performed significantly higher than the 1C PUR adhesives joints, no significant difference was observed within the 1C PUR variants. All 1C PUR adhesive bonds were characterized by a similar wood failure percentage in standard climate conditions of around $30-40 \%$.

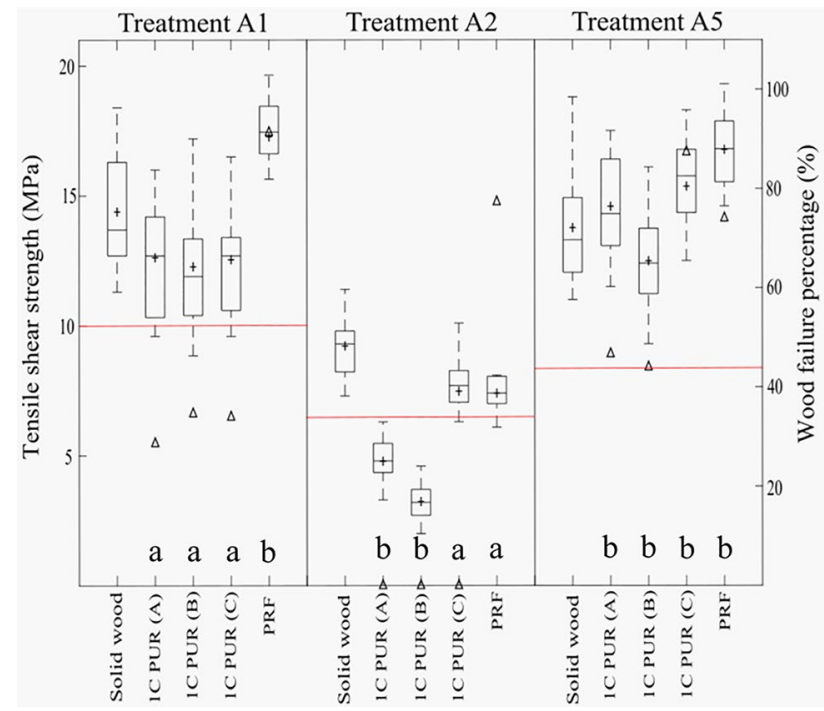

Fig. 2 Boxplots of tensile shear strength (mean value marked as cross) and wood failure (triangle) after treatment A1, A2 and A5 for the adhesives 1C PUR (A, B and C) and PRF $(n=15)$. Boxplots indicate median, interquartile range and minimum and maximum are shown as whiskers. Horizontal line marks standards requirement following EN 302-1. Statistically homogenous groups are indicated with letter a, significantly different variants with letter b. (ANOVA, significance level 5\%)
The storage in water and subsequently testing in wet state (A2) showed a considerable reduction in tensile shear strength and wood failure percentage for lap-joints, including the solid wood reference, in comparison to the performance in dry climate (A1). However, the PRF maintained its high WFP. Characteristic for all 1C PUR variants was the absence of the wood failure for all cases. While the 1C PUR $\mathrm{C}$ with primer application demonstrated a similar tensile shear strength to PRF, the other PUR adhesive assemblies performed below $50 \%$ of the solid wood value reference. 1C PUR B was significantly lower in tensile shear strength than 1C PUR A. Despite no significant difference in strength, the type of failure between 1C PUR C and PRF differed considerably. The application of a primer led to a significant increase in tensile shear strength compared to the same adhesive applied without any adhesion promoter. Considering the standard requirements for $\mathrm{A} 2$ conditions, $1 \mathrm{C}$ PUR A and B were not able to reach the $6 \mathrm{MPa}$ threshold value.

For treatment A5, specimens were re-conditioned to their original mass in standard climate, after boiling in water and cold-water storage. All adhesives joints were able to reach similar or even better values compared to their standard climate reference, which was in accordance with another study (Kläusler et al. 2014a, b). Yet, significant differences appeared between all variants. The variant with applied primer (1C PUR C) obtained a significantly higher tensile shear strength than the variant 1C PUR B without primer and nearly the same as the variant 1C PUR A without primer, but this time with higher WFP than for the PRF.

As a main result from the macroscopic test it can be concluded that the investigated two commercial 1C PUR systems meet standard requirements when tested in dry ambient, while they lack in performance when tested in wet conditions. The well-established PRF adhesive joints were able to meet all standard requirements. The application of the primer (1C PUR C) sufficiently improved the bonding performance for surpassing the standard requirements in wet conditions (A2). However, the primer application did not increase the wood failure percentage for treatment A2.

\subsection{Gravimetrically determined hydroxyl group accessibility to $D_{2} O$ vapor}

The results of the DVS experiments are depicted in Fig. 3. The reference obtained an average value of around 7.5 $\mathrm{mmol} / \mathrm{g}$ accessible hydroxyl groups for early wood of beech.

No difference was observed between the reference and the samples immersed in $0.1 \%$ primer solution. The samples treated with $1 \%$ primer concentration obtained higher scattering and two out of three values with a lower amount of accessible hydroxyl groups, but no statistically significant trend could be determined. The variant exposed to $10 \%$ primer concentration showed a substantial decrease 
Fig. 3 Single values of hydroxyl accessibility at $95 \%$ relative humidity determined gravimetrically by DVS for European beech early wood, with different primer concentrations, and wood powder previously treated by two different types of extraction

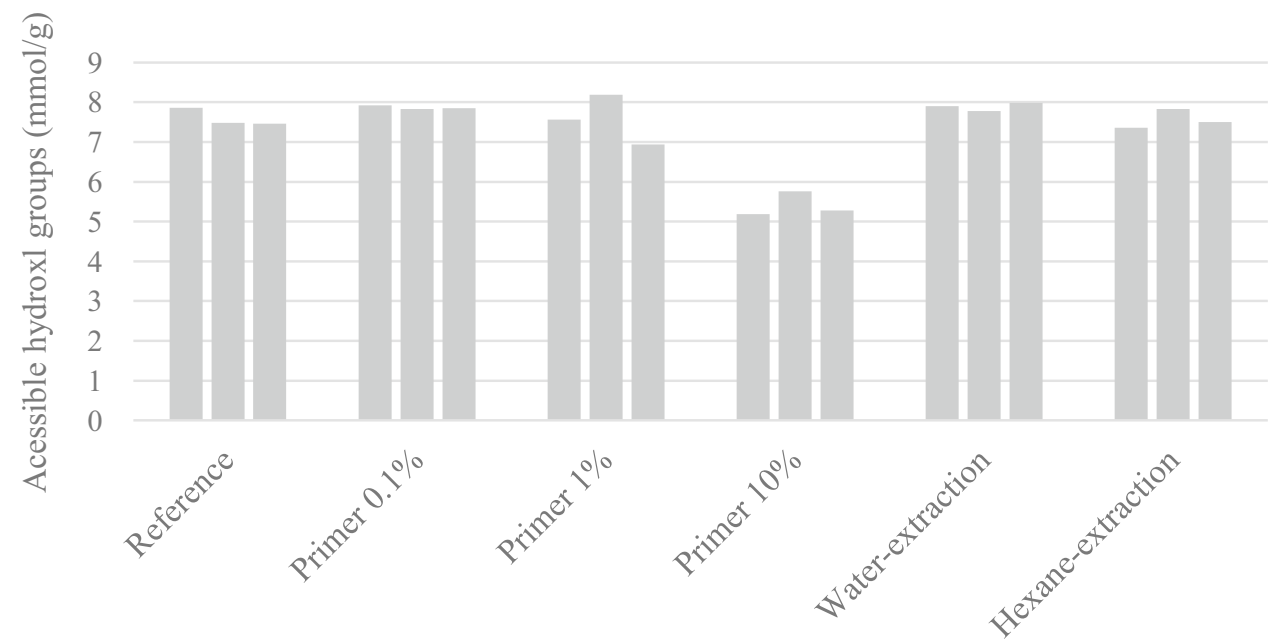

in hydroxyl group accessibility down to approximately two thirds of the reference accessible hydroxyl groups.

It is proposed that the primer may deposit on the wood polymer hydroxyl groups and could therefore block the access to deuteration in high concentrations of $10 \%$. However, this concentration exceeds industrial primer application. Own studies with samples that have been sprayed with industrial application devices using a common spread rate and concentration showed a similar trend for samples but a considerable smaller influence on the hydroxyl accessibility (results not shown).

The extraction treatments applied to the beech wood did not show a difference in hydroxyl group accessibility. The hot water extraction aimed to mainly dissolve polar components such as tannins, organic salts and carbohydrates. Extraction with hexane focused on dissolving of mainly non-polar extractives such as fats, waxes and phenols (Sixta 2006). The hypothesis of the study was that some extractives can reduce the hydroxyl group accessibility by creating a surficial chemical weak boundary layer of water-soluble extractives, and when the extractives were dissolved, the amount of accessible hydroxyl groups would be expected to increase. While the hot-water extraction showed consistently high hydroxyl group accessibility, a slightly higher scattering was observed for hexane-extracted wood, while no significant difference to the reference could be detected.

\subsection{Nanoindentation}

Optical focusing, proper positioning and subsequent tip approach with the nanoindentation device was not possible with the samples being covered in water. Therefore, after full sample immersion in water for $48 \mathrm{~h}$, the water level was lowered below the sample surface $120 \mathrm{~min}$ prior to the first measurement for the condition "wet storage". The ongoing shrinking of the swollen sample required permanent focus adjustment for each measurement. The results of the nanoindentation (NI) experiments on bulk materials (adhesive, wood cell walls) are summarized in Fig. 4. In general, the PRF adhesive revealed an approximate three times higher reduced (red.) E-modulus and an approximate four times higher hardness than the polyurethane adhesives in dry conditions, which is in accordance with other studies (Amman et al. 2013; Stoeckel et al. 2013) performed on similar substrates. Comparing all 1C PUR variants in room climate, no significant difference in mechanical properties was found. During storage in water, the red. E-modulus and hardness of all adhesive systems dropped considerably. Noticeable is the high relative change of PRF in comparison to all $1 \mathrm{C}$ PUR variants in terms of red. E-modulus and hardness. The polyurethane adhesives were reduced in red. E-modulus to around $70 \%$ and PRF to $10 \%$ of its initial values at room climate. The hardness of polyurethane adhesives was reduced to $30-40 \%$ and that of PRF to $30 \%$ of its original value.

No significant influence on bulk adhesive properties was observed when a primer was used. In general, the investigations on the bond line and the results for the bulk adhesive were comparable with earlier studies on moisture influence tested on cured adhesive polymer films (Konnerth et al. 2010). While the differences in dry and wet conditions for red. E-modulus and hardness were quite similar, the $1 \mathrm{C}$ PUR C had significantly lower values for red. E-modulus and hardness in re-dried conditions for the bulk adhesive as well as the cell wall. After testing in wet conditions, the samples were dried for two days in room climate. All bulk adhesives were able to re-gain a considerable part of their original mechanical properties in room climate. Indentations in the wood cell showed that the red. E-modulus at room climate was somewhat higher for the wood cells next to PRF compared to wood cell walls in contact with the group of $1 \mathrm{C}$ PUR. However, this effect is superimposed by a high degree of scattering resulting from the natural variability of the 
Fig. 4 Results from nanoindentation on bulk adhesive and bulk secondary S2 wood cell walls from the interphase region for red. E-modulus $\left(\mathrm{E}_{\mathrm{r}}\right)$ and hardness in room climate, during water storage and in redried conditions for specimens bonded with the adhesives 1C PUR (A, B, C) and PRF $(n=12)$. Boxplots indicate median, interquartile range and minimum and maximum are shown as whiskers. Statistically homogenous groups are indicated with letter a, significantly different variants with letter $b$. (ANOVA, significance level $5 \%)$

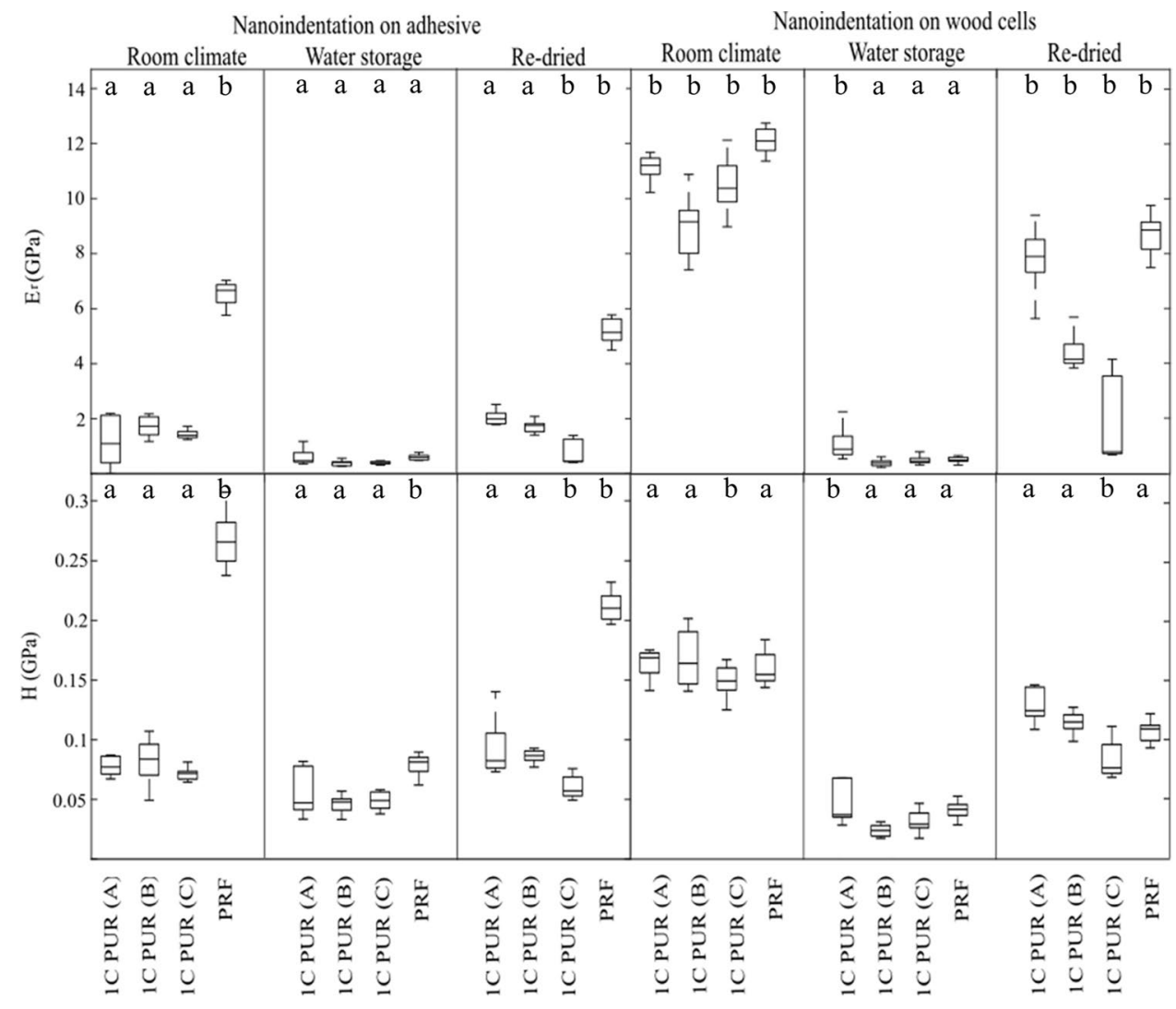

wood substrate. Higher mechanical values for cell walls in contact with in-situ polymerizing adhesives (Frihart 2012), such as the PRF used, can generally be expected by the penetration of low-molecular weight substances from the liquid PRF into the wood cell prior to curing. As a consequence, stiffening of the wood cell walls is frequently observed (e.g.,Gindl et al. 2004; Konnerth et al. 2006). However, this effect was not visible for the hardness of wood cells near PRF measured in other studies (Obersriebnig et al. 2013). Between the 1C PUR variants, wood cells of 1C PUR A and 1C PUR C did not show any significant difference, while 1C PUR B was significantly lower. Due to the incapability of penetrating the cell walls, this difference may have its origin rather in the variability of the wood structure than by the influence of the adhesive.

After water storage, variant 1C PUR A showed significantly higher red. E-modulus and hardness compared to the remaining variants, which did not show significant differences, including the PRF variant. After drying for two days, the red. E-modulus differed significantly for all variants. However, for hardness, only 1C PUR C showed a significantly lower hardness. As moisture is a main bias for mechanical properties of polymers, differences in drying rate of the individual adhesives and assemblies may be assumed. It remains unclear whether the mechanical properties are able to re-gain their original values for the case of longer storage times. Macroscopic properties observed using the lap-joints described above might be an indicator that properties lost during wet storage may be recuperated.

The results of the specific work of indentation at the direct interface between adhesive and wood, separated into the different contact regions between adhesive and the wood cell wall S2 and S3, are depicted in Fig. 5.

The specific work of indentation presented in Fig. 5 consists mainly of the work consumed for deforming the wood cell wall and the adhesive. Only a comparably small amount of around $10-20 \%$ can be attributed to real adhesion as expected by Obersriebnig et al. (2012). However, a visible crack was observed by the authors, which exceeded the size of the indentation tip towards a partial delamination of both surfaces.

Due to methodological restrictions, differences in adhesion can only be observed when mechanical properties of the individual constituents are comparable. As a consequence, only differences in specific work of indentation between different contact regions (S2 vs. S3) of one adhesive assembly and condition state may be interpreted as adhesion differences. In contrast, the considerable differences between the specific work of indentation of different adhesives, as visible for PRF and the 1C PUR versions, may not be interpreted as differences in adhesion, but have their origin mainly 


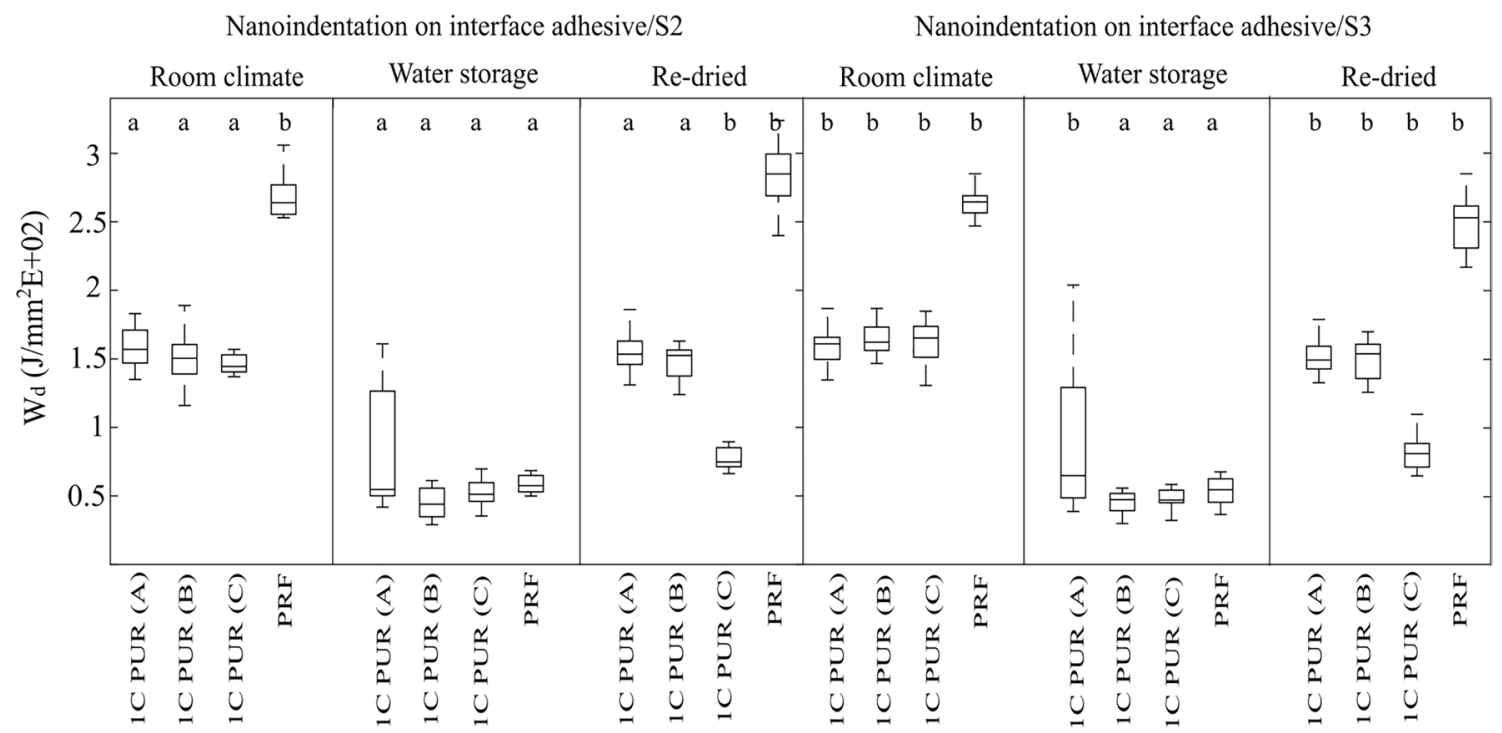

Fig. 5 Specific work of indentation $\left(\mathrm{W}_{\mathrm{d}}\right)$ for indentation at the interfaces between adhesive/secondary wood cell wall S2 and adhesive/ lumen S3 in room climate, during water storage and in re-dried conditions for different 1C PUR (A-C) and PRF adhesives $(n=12)$. Box-

from differences in mechanical properties of the constituent phases (cell wall, adhesive) in their corresponding state.

Considering these restrictions for interpreting the specific work of indentation, PRF was found to adhere similar to S2 and $\mathrm{S} 3$ cell wall areas in dry state, as well as after water storage. Only after re-drying, the adhesion towards S3 cell wall areas may be considered to be lower. For 1C PUR A, specific work of indentation at the interfaces between adhesive and both cell wall areas S2 and S3 was found to be similar in all three conditions. Since the similar 1C PUR adhesive was used to produce variant $\mathrm{B}$ and the primered variant $\mathrm{C}$, a careful comparison can be drawn. 1C PUR B and the primered variant of the same adhesive 1C PUR C showed higher specific work of indentation at the adhesive/S3 interface in room climate, while no difference could be found for the other climatic conditions.

Before performing the present work, higher adhesion between PUR adhesive and cell wall areas was hypothesized when using a primer, especially in wet state as a high amount of adhesion failure (lack of wood failure) is frequently observed for PUR-wood bonds (Fig. 2, A2 condition). Comparing the specific work of indentation at the interface of 1C PUR B and the primered variant of the same adhesive 1C PUR C, in wet state an insignificant specific work of indentation is visible for 1C PUR C. In re-dry state, specific work of indentation of $1 \mathrm{C}$ PUR C is significantly below the value of $1 C$ PUR B. As considerable differences in bulk mechanical properties of the two PUR assemblies are evident for the same conditions, deriving information about adhesion differences is not possible. plots indicate median, interquartile range and minimum and maximum are shown as whiskers. Statistically homogenous groups are indicated with letter a, significantly different variants with letter $b$. (ANOVA, significance level 5\%)

\subsection{Overall discussion}

Lap-shear joints of beech wood demonstrated once again (Konnerth et al. 2016; Clerc et al. 2018) that the used PRF adhesive is capable of meeting standard requirements for all conditions. However, a formaldehyde free and colorless alternative for safely bonding hardwood is frequently desired.

The used 1C PUR systems showed good performance in dry and re-dried conditions, but a primer was needed to surpass standards requirements in wet conditions on beech wood. Despite improving strength, the application of the primer did not lead to an improvement in wood failure percentage. Contrary, another study (Lüdtke et al. 2015) showed that WFP can be increased by using a primer. This difference may be explained by possible differences in the primer application, or by the small processing window of the primer (Clerc et al. 2018).

The investigated hydroxyl group accessibility of European beech wood was in accordance with findings by Tarmian et al. (2017). They further showed only minor differences between the hydroxyl group accessibility of European beech, spruce and pine wood. In contrast, Teleman et al. (2002) found a lower amount of accessible hydroxyl groups for hardwoods, for example beech wood, due to the beech's lower amount of hydroxyl groups of its hemicelluloses. However, this possible disadvantage of beech wood may only be a subordinated factor to explain the more challenging bonding of hardwood in comparison to softwood. Far more important for hardwood bonding could be their higher density as well as higher swelling and shrinking coefficients 
(Niemz and Sonderegger 2017). These properties result in higher stresses in the bond region as a result of changing moisture conditions.

The removal of polar and nonpolar extractives did not show any considerable influence on the hydroxyl group accessibility of beech wood. Its low extractive content of around 2\% based on the dry wood mass (Jiang et al. 2014) could be the reason for not revealing a possible influence. Hence, this approach could have more impact on wood species with considerably higher extractive contents such as larch or pine.

The primer is expected to enhance wetting of 1C PUR on hardwood as well as to increase the adhesion. With the methods used, an improvement of the adhesion at the interface due to primer application could not be found. As the mechanical properties of the bulk wood cell wall remained at a lower level after the two days of re-drying, a possible influence of the primer on the water absorption and/or release rate in the interphase area could be assumed. Studies by Väisänen et al. (2018) demonstrated that there is a connection between the equilibrium moisture content and the accessibility of hydroxyl groups, while another study revealed only poor correlation (Rautkari et al. 2013). In this regard, the deep penetration of the primer in the wood cell walls, as shown by Casdorff et al. (2018), might be favorable. However, this finding could not be validated in the present study, as the amount of primer necessary to decrease the hydroxyl accessibility noticeably exceeds industrial application rates by far. Therefore, a reduction in hydroxyl group accessibility under optimal industrial primer application cannot be proven.

As a novelty, the nanoindentation experiments revealed that water-stored wood-adhesive composites can also be tested in wet conditions. However, analyzing the specific work of indentation did not show any influence of the applied primer on the adhesion in different climate conditions. The proportionally higher reduction in red. E-modulus and hardness of PRF can be attributed to a softening of the polymers as a result of water uptake. Wimmer et al. (2013) revealed that PRF adhesive can take up to $18 \%$ moisture, while 1C PUR only gained $3.5 \%$, which was explained by the process of polycondensation and the production of methylol phenol derivates. The involved hydroxyl groups may take up two water molecules (Bentz and Neville 1949). Furthermore, the hydromechanical performance of PRF was considered to be similar to wood (Musznyski et al. 2002). In combination with cell wall impregnation and the reduction in local swelling and shrinking in the interphase, PRF is capable of creating a moisture-resistant composite with high mechanical strength even in wet conditions.

Kläusler et al. (2013) showed that the tensile strength of 1C PUR polymer films was reduced by $19-30 \%$ when ambient moisture was increased from standard climate to a relative humidity of $95 \%$. In addition, its E-modulus was reduced in these conditions between 31-56\%. In comparison, PRF did not show a decline in tensile strength with increasing moisture content, but the E-modulus was significantly reduced to $50 \%$. For polyurethane, it can be expected that water uptake is also leading to structural changes such as free volume variations, relaxation effects and changes in visco-elastic behavior (Smith et al. 2004).

\section{Conclusion}

The novel and challenging approach to characterize woodadhesive interfaces of bonds in wet conditions by nanoindentation extends possible applications for nanoindentation and was expected to provide new insights into the mechanisms how a primer is affecting PUR bonds. In contrast to the authors' assumptions, no measurable effect of the primer on the local adhesion between adhesive and cell wall by specific work of indentation could be observed.

While macroscopic mechanical performance of PRF adhesive bonds are on a high level, the storage in water showed a dramatic reduction in mechanical properties of the PRF adhesive itself. This effect was much less pronounced for the polyurethane adhesives. No direct influence of the primer on the local micro-mechanical properties of the bonding line could be found in dry and wet conditions. Only after re-drying, the mechanical properties of the wood cell walls pre-treated with the primer remained longer on a lower level, while other adhesives regained their original values already. It was further shown that the primer application can reduce the hydroxyl accessibility of beech wood, when applying high spread rates. The mechanism of the primer responsible for improving 1C PUR adhesive bonds is still not fully understood and requires further research.

Acknowledgements The authors thank the Swiss Innovation agency Innosuisse for the financial support.

Funding This work was supported by the Swiss Innovation Agency Innosuisse (Project No. 18061.1). Open Access funding provided by University of Natural Resources and Life Sciences Vienna (BOKU).

\section{Compliance with ethical standards}

Conflict of interest On behalf of all authors, the corresponding author states there is no conflict of interest.

Open Access This article is licensed under a Creative Commons Attribution 4.0 International License, which permits use, sharing, adaptation, distribution and reproduction in any medium or format, as long as you give appropriate credit to the original author(s) and the source, provide a link to the Creative Commons licence, and indicate if changes were made. The images or other third party material in this article are included in the article's Creative Commons licence, unless indicated otherwise in a credit line to the material. If material is not included in 
the article's Creative Commons licence and your intended use is not permitted by statutory regulation or exceeds the permitted use, you will need to obtain permission directly from the copyright holder. To view a copy of this licence, visit http://creativecommons.org/licenses/by/4.0/.

\section{References}

Amen-Chen C, Gabriel J (2015) Wet adhesion durability improvement of polyurethane wood adhesives with primer. Eur J Wood Prod 73:697-700. https://doi.org/10.1007/s00107-015-0942-9

Ammann S, Obersriebnig M, Konnerth J, Gindl-Altmutter W, Niemz P (2013) Comparative adhesion analysis at glue joints in European beech and Norway spruce wood by means of nanoindentation. Int J Adhes Adhes 50:45-49. https://doi.org/10.1016/j. ijadhadh.2013.12.023

Ammann S, Schlegel S, Beyer M, Aehlig K, Lehmann M, Jung H, Niemz P (2016) Quality assessment of glued ash wood for construction engineering. Eur J Wood Prod 74:67-74. https://doi. org/10.1007/s00107-015-0981-2

Bentz RW, Neville HA (1949) Water content of hydrophilic phenolformaldehyde resins: vapor pressure-temperature relationships. J Polym Sci 4 6:673-688

Casdorff K, Kläusler O, Gabriel J, Amen C, Lehringer C, Burgert I, Keplinger T (2018) About the influence of a water-based priming system on the interactions between wood and one-component polyurethane adhesive studied by atomic force microscopy and confocal Raman spectroscopy imaging. Int J Adhes Adhes 80:52-59. https://doi.org/10.1016/j.ijadhadh.2017.10.001

Clerc G, Lehmann M, Gabriel J, Salzgeber D, Pichelin F, Strahm T, Niemz P (2018) Improvement of ash (Fraxinus excelsior L:) bonding quality with one-component polyurethane adhesive and hydrophilic primer for load-bearing application. Int J Adhes Adhes 85:303-307. https://doi.org/10.1016/j.ijadh adh.2018.06.017

Dunky M, Niemz P (2002) Holzwerkstoffe und Leime (engineered wood products and adhesives). Springer, New York

EN 302-1 (2013) Adhesives for load-bearing timber structures. Test methods-part 1: determination of longitudinal tensile shear strenght. European Committee for Standardization, Brussels

Frihart CR (2012) Wood adhesion and adhesives. Handbook of wood chemistry and wood composites. CRC Press, Florida, pp 256-313

Gindl W, Schöberl T, Jeronimidis G (2004) The interphase in phenolformaldehyde and polymeric methylene di-phenyl-di-isocyanate glue lines in wood. Int J Adhes Adhes 24:279-286. https://doi. org/10.1016/j.ijadhadh.2003.10.002

Jakes JE, Frihart CR, Beecher JF, Moon RJ, Stone DS (2008) Experimental method to account for structural compliance in nanoindentation measurements. J Mater Res 23:1113-1125. https://doi. org/10.1557/jmr.2008.0131

Jakes JE et al (2015) Synchrotron-based X-ray fluorescence microscopy in conjunction with nanoindentation to study molecular-scale interactions of phenol-formaldehyde in wood cell walls. ACS Appl Mater Interfaces 7 12:6584-6589. https://doi.org/10.1021/ am5087598

Jiang Y, Schaffrath J, Knorz M, Winter S (2014) Bonding of various wood species-studies about their applicability in glued laminated timber. In: materials and joints in timber structures. RILEM Bookseries 9:365-374. https://doi.org/10.1007/978-94-007-7811-5_33

Kläusler O, Clauss S, Lübke L, Trachsel J, Niemz P (2013) Influence of moisture on stress-strain behavior of adhesives used for structural bonding of wood. Int J Adhes Adhes 44:57-65. https://doi. org/10.1016/j.ijadhadh.2013.01.015
Kläusler O, Rehm K, Elstermann F, Niemz P (2014a) Influence of wood machining on tensile shear strength and wood failure percentage of one-component polyurethane bonded wooden joints after wetting. Int Wood Prod J 5:18-26. https://doi.org/10.1179/2 042645313Y.0000000039

Kläusler O, Hass P, Amen C, Schlegel S, Niemz P (2014b) Improvement of tensile shear strength and wood failure percentage of 1C PUR bonded wooden joints at wet stage by means of DMF priming. Eur J Wood Prod 72:343-354. https://doi.org/10.1007/ s00107-014-0786-8

Konnerth J, Gindl W, Harm M, Müller U (2006) Mechanical characterization of woodadhesive interphase cell walls by nanoindentation. Holzforschung 60 4:429-433. https://doi.org/10.1515/ HF.2006.067

Konnerth J, Gierlinger N, Keckes J, Gindl W (2009) Actual versus apparent within cell-wall variability of nanoindentation results from wood cell walls related to cellulose microfibrill angle. J Mater Sci 44:4399-4406. https://doi.org/10.1007/s1085 3-009-3665-7

Konnerth J, Stöckel F, Gindl W, Müller U (2010) Elastic properties of adhesive polymers. III. Adhesive polymer FIlms under dry and wet conditions characterized by means of nanoindentation. J Appl Polym Sci 118:1331-1334. https://doi.org/10.1002/app.32342

Konnerth J, Kluge M, Schweizer G, Miljkovic M, Gindl-Altmutter W (2016) Survey of selected adhesive bonding properties of nine European softwood and hardwood species. Eur J Wood Prod 74:809-819. https://doi.org/10.1007/s00107-016-1087-1

Lüdtke J, Amen C, van Ofen A, Lehringer C (2015) 1C-PUR-bonded hardwoods for engineered wood products: influence of selected processing paramters. Eur J Wood Prod 73:167-178. https://doi. org/10.1007/s00107-014-0875-8

Muszynski L, Wang F, Shaler SM (2002) Short-term creep tests on phenol-resorcinol-formaldehyde (prf) resin undergoing moisutre content changes. Wood Fiber Sci 34 4:612-624

Niemz P, Sonderegger W (2017) Holzphysik-Physik des Holzes und der Holzwerkstoffe (Wood physics — wood and engineered wood products physics). Fachbuchverlag im Carl Hanser Verlag, Munich

Obersriebnig M, Veigel S, Gindl-Altmutter W, Konnerth J (2012) Determination of adhesive energy at the wood cell-wall/UF interface by nanoindentation (NI). Holzforschung 66:781-787. https:// doi.org/10.1515/hf-2011-0205

Obersriebnig M, Konnerth J, Gindl-Altmutter W (2013) Evaluating fundamental position-dependent differences in wood cell wall adhesion using nanoindentation. Int J Adhes Adhes 40:129-134. https://doi.org/10.1016/j.ijadhadh.2012.08.011

Ohnesorge D, Richter K, Becker G (2010) Influence of wood properties and bonding parameters on bond durability of European Beech (Fagus sylvatica L.) glulams. Ann Forest Sci 67 6:601-601. https ://doi.org/10.1051/forest/2010002

Oliver WC, Pharr GM (1992) An improved technique for determining hardness and elastic modulus using load and displacement sensing indentation experiments. J Mater Res 7 6:1564-1582. https://doi. org/10.1557/JMR.1992.1564

Rautkari L, Hill CAS, Jalaludin Z, Curling S, Ormondroyd G (2013) What is the role of the accessibility of wood hydroxyl groups in controlling moisture content? J Mater Sci 48:6352-6356. https:// doi.org/10.1007/s10853-013-7434-2

Ren D, Frazier CE (2012) Wood/adhesive interactions and the phase morphology of moisture-curing polyurethane wood adhesives. Int J Adhes Adhes 34:55-61. https://doi.org/10.1016/j.ijadh adh.2011.12.009

Richter K (1999) Feuchtebeständige Verklebung von Brettschichtholz durch den Einsatz eines Haftvermittlers (Moisture-resistant bonding of glued laminated timber through the use of adhesion-promoting agent). www.forum-holzbau.ch 
Rindler A, Pöll C, Müller U, Hansmann C, Konnerth J (2018) Moisture related elastic and viscoelastic behaviour of wood adhesives by means of in-situ nanoindentation. Int J Adhes Adhes 85:123-129. https://doi.org/10.1016/j.ijadhadh.2018.06.004

Sepall O, Mason SG (1961) Hydrogen exchange between cellulose and water. I. Measurement of acessibility. Can J Chem 39:1934-1943. https://doi.org/10.1139/v61-260

Sixta H (2006) Handbook of pulp. Wiley, Weinheim

Smith AL, Mulligan RB, Shirazi HM (2004) Determing the effects of vapor sorption in polymers with quart crystal microbalance/heat conduction calorimeter. J Polym Sci B Polym Phys 42:3893-3906. https://doi.org/10.1002/polb.20243

Stoeckel F, Konnerth J, Gindl-Altmutter W (2013) Mechanical properties of adhesives for bonding wood-a review. Int J Adhes Adhes 45:32-41. https://doi.org/10.1016/j.ijadhadh.2013.03.013

Tarmian A, Burgert I, Thybring E (2017) Hydroxyl accessibility in wood by deuterium exchange and ATR-FTIR spectroscopy: methodological uncertainties. Wood Sci Technol 51:845-853. https:// doi.org/10.1007/s00226-017-0922-9

Teleman A, Tenkanen M, Jacobs A, Dalman O (2002) Characterization of $O$-acetyl-(4- $O$-methlyglucurono)xylan isolated from birch and beech. Carbohydr Res 337:373-377. https://doi.org/10.1016/ S0008-6215(01)00327-5
Thybring E, Thygesen LG, Burgert I (2017) Hydroxyl accessibility in wood cell walls as affected by drying and re-wetting procedures. Cellulose 24:2375-2384. https://doi.org/10.1007/s1057 0-017-1278-x

Väisänen S, Pönni R, Hämäläinen A, Vuorinen T (2018) Quantification of acessible hydroxyl groups in cellulosic pulps by dynamic vapor sorption with deuterium exchange. Cellulose 2512:6923-6934. https://doi.org/10.1007/s10570-018-2064-0

Wimmer R, Tsui TY, Lucas BH, Oliver WC (1997) Longitudinal hardness and Young`s modulus of spruce radial tracheid secondary walls using nanoindentation technique. Wood Sci Technol 31:131-141. https://doi.org/10.1007/BF00705928

Wimmer R, Kläusler O, Niemz P (2013) Water sorption mechanisms of commercial wood adhesive films. Wood Sci Technol 47 4:763775. https://doi.org/10.1007/s00226-013-0538-7

Zhang Y, Liu C, Wang S, Wu Y, Meng Y, Cui J, Zhou Z, Ma L (2015) The influence of nanocellulose and silicon dioxide on the mechanical properties of the cell wall with relation to the bond interface between wood and urea formaldehyde resin. Wood Fiber Sci 47 $3: 1-9$

Publisher's Note Springer Nature remains neutral with regard to jurisdictional claims in published maps and institutional affiliations. 